\title{
THE EFFECT OF COVID-19 PANDEMIC ON THE FREQUENCY OF SPINAL TRAUMA: AN EPIDEMIOLOGICAL STUDY
}

\author{
๑ Ömer Özdemir, ๑ Furkan Diren, ๑ Osman Boyalı, ๑ Murat Kahraman, ๑ Serdar Kabataș, ๑ Erdinç Civelek
}

University of Health Sciences Turkey, Gaziosmanpaşa Training and Research Hospital, Clinic of Neurosurgery, İstanbul, Turkey

Objective: This study aims at comparing the patients with spinal trauma in the Coronavirus disease-2019 pandemic era and pre-pandemic era. Materials and Methods: Patient records for a 9-month period of pandemic (April 1, 2020 - December 31, 2020) and the same period of the previous year (April 1, 2019 -December 31,2019) were retrospectively collected. These 2 periods were compared in terms of the total number of patients with spinal trauma, the type of injuries, the level of injuries in the spine, the treatment methods applied, and whether there was a neurological deficit. The first group was called as pandemic group (PG) and the latter as control group (CG). The differences between them were statistically examined.

Results: The study sampled 278 patients (CG: 203 patients, PG: 75 patients). It was detected that the number of patients with spinal trauma in the PG dropped by $60 \%$ compared to the CG. The most frequent cause of spinal trauma for both groups was traffic accidents. No statistically significant difference was detected in terms of the type, level and severity of injuries, neurological examination findings and method of treatment $(p>0.05)$. However, the rate of indoor or outdoor falls were significantly different between the two groups $(p=0.002)$.

Conclusion: It has been determined that the pandemic-induced social isolation and lockdown process is an important factor in the primordial prevention of spinal trauma. With the result obtained, we think that if adequate and correct measures are taken, the number of spinal traumas will continue to remain low in the post-pandemic period as well.

Keywords: COVID-19 pandemic, spinal trauma, epidemiological study

\section{INTRODUCTION}

Spinal trauma-related spinal fractures and spinal cord injuries may lead to significant loss in the quality of life, and they are among the most common causes of mortality and morbidity ${ }^{(1,2)}$. Spinal injuries are seen in $10 \%$ of trauma patients and have a higher mortality rate compared to other injuries ${ }^{(3)}$. Studies have reported that the number of spinal fracture incidences varies between $16-117 / 100.00^{(4-6)}$. Compared with the other organ injuries, spinal fractures and spinal injuries cause more severe functional losses and impairment in activities ${ }^{(7)}$. The most effective way to prevent spinal traumas is to describe the problem in various populations and try to identify possible risk factors. Most of the traumas are caused by traffic accidents and high and short-distance falls. While the most common causes of trauma in the young population are traffic accidents and high falls, severe spinal traumas are observed even in shortdistance falls in the elderly population due to osteoporosis $s^{(4,8)}$. This study seeks examine the impact of social isolation and lockdowns induced by the coronavirus disease-2019 (COVID-19) pandemic which has affected the whole world over the past year, with a view to determine the risk factors that cause spinal traumas. The purpose of this study is to investigate the frequency of the hospital visits by spinal trauma patients within the same periods of the pandemic and the year before pandemic and to reveal the general characteristics, similarities and differences of the patients. Our hypothesis is that the number of spinal trauma patients visiting the emergency department decreased over the past year which was affected by the COVID-19 pandemic.

\section{MATERIALS AND METHODS}

The present research conducts a retrospective single-center analysis. The data of each patient who visited the emergency department of our hospital between April 1 and December 31, 2020 and diagnosed with vertebral fracture or spinal cord injury were retrospectively collected. Only the patients visiting the emergency department were included in the sample. The demographic information, diagnosis, type of treatment and duration of hospitalization of these patients were obtained from the medical records. The patients visiting the emergency department in a period of the pandemic year were compared with those making such visits with the same complaints in the same period of the previous year (1 April-31 December 2019).

Address for Correspondence: Ömer Özdemir, University of Health Sciences Turkey, Gaziosmanpaşa Training and Research Hospital, Clinic of Neurosurgery, istanbul, Turkey

Phone: +90 5324936519 E-mail: dromerozdemir1982@gmail.com Received: 17.01.2022 Accepted: 31.01.2022

ORCID ID: orcid.org/0000-0003-3783-0203

${ }^{\circ}$ Copyright 2022 by the Turkish Spine Society / The Journal of Turkish Spinal Surgery published by Galenos Publishing House. 
The patients who visited in the pandemic period was called as the pandemic group (PG), and those from the previous year as the control group (CG). Surgical indications of the patients and the level of injuries were recorded. Thoracolumbar injury classification and severity score was used to evaluate spinal cord injuries related to thoracic and lumbar fracture and Subaxial Cervical Injury Classification and Severity score was used to evaluate spinal cord injuries related to cervical fracture. The same procedure was applied to the patients in both PG and CG. The data of the patients were obtained by searching for specific diagnostic codes in the institutional database. Then the clinical information was taken from each patient's medical records.

All procedures were carried out in accordance with the 1964 Helsinki declaration. Written informed consent for scientific purposes and clinical data collection were obtained from patients according to institutional protocol. Ethical approval was obtained from both the local ethics committee University of Health Sciences Turkey, Gaziosmanpaşa Training and Research Hospital (approval date: 28.04.2021, approval number: 259) and the Ministry of Health.

\section{Statistical Analysis}

Statistical Package for the Social Sciences version 25.0 software (SPSS Inc., Chicago, IL, USA) was used for data analysis. Mean, median, standard deviation, minimum, maximum, frequency and percentage were used as descriptive methods. Shapiro-Wilk test was performed to assess the normality of the distribution. According to the results of normality analyses, the data was not normally distributed. For the comparison of categorical data, the chi-square test was applied. The Mann-Whitney $U$ test was used for comparison of means. The statistical significance level was set at $p<0.05$.

\section{RESULTS}

A total of 278 patients, 203 patients in CG and 75 patients in PG, were included in the study. It was observed that the number of patients decreased by $63 \%$ in the pandemic year compared to the pre-pandemic era. The distribution of spinal trauma patients who visited emergency department each month is given in Figure 1. No statistically significant difference was found between the PG and the CG in terms of gender, age and length of hospital stay (Table 1). $39 \%$ of the CG consisted of female patients and $61 \%$ of male while $42 \%$ of the PG consisted of female patients and $58 \%$ of male. The mean ages of the CG and the $P G$ were $38 \pm 17.53$ and $41 \pm 19.18$ respectively. While the length of hospital stay was $5 \pm 4.48$ in the CG, it was $2 \pm 4.12$ in the PG (Table 1).

There was no statistical difference between the PG and the CG in terms of the type of injury, the severity of injury, the level of injury in the spine, the presence of neurological deficits, and the treatment methods (Table 2).

The most common causes of trauma in both control and PGs were traffic accidents (CG: 40\%, PG: 39\%). Lumbar injury was the most common in both groups (CG: 67\%, PG: 55\%). Likewise, there was no difference between the two groups in terms of development of neurological deficits (CG: 10\%, PG: 13\%). While $53 \%$ of the patients in the CG received surgical treatment, $44 \%$ of the patients in the PG received this treatment (Table 2). Among the patients with fall-related trauma, a significant difference was found in terms of indoor falls (CG: 45\%,PG: $85 \%$ ) and outdoor falls (CG: 55\%, PG: 15\%) ( $p=0.002)$ (Table 3).

\section{DISCUSSION}

In December 2019, a series of new infectious respiratory diseases of unknown origin were observed in Wuhan, China.

Table 1. Demographic characteristics of the groups

\begin{tabular}{|c|c|c|c|}
\hline & Control & $\begin{array}{l}\text { Pandemic } \\
\text { group }\end{array}$ & p-value \\
\hline $\begin{array}{l}\text { Sex (n F/M) } \\
(\% F / M)\end{array}$ & $\begin{array}{l}80 / 123 \\
(39 / 61)\end{array}$ & $\begin{array}{l}32 / 43 \\
(42 / 58)\end{array}$ & $0.623^{1}$ \\
\hline $\begin{array}{l}\text { Mean age } \\
(\min -\max )\end{array}$ & $\begin{array}{l}38 \pm 17.53 \\
18-78\end{array}$ & $\begin{array}{l}41 \pm 19.18 \\
14-81\end{array}$ & $0.876^{2}$ \\
\hline $\begin{array}{l}\text { Mean hospital stay (day) } \\
\text { (min-max) }\end{array}$ & $\begin{array}{l}5 \pm 4.48 \\
1-45\end{array}$ & $\begin{array}{l}2 \pm 4.12 \\
1-24\end{array}$ & $0.246^{2}$ \\
\hline $\begin{array}{l}{ }^{1} \text { Chi-square test } \\
{ }^{2} \text { Mann-Whitney U test } \\
\text { F: Female, M: Male, min: Mini }\end{array}$ & max. Maxi & & \\
\hline
\end{tabular}

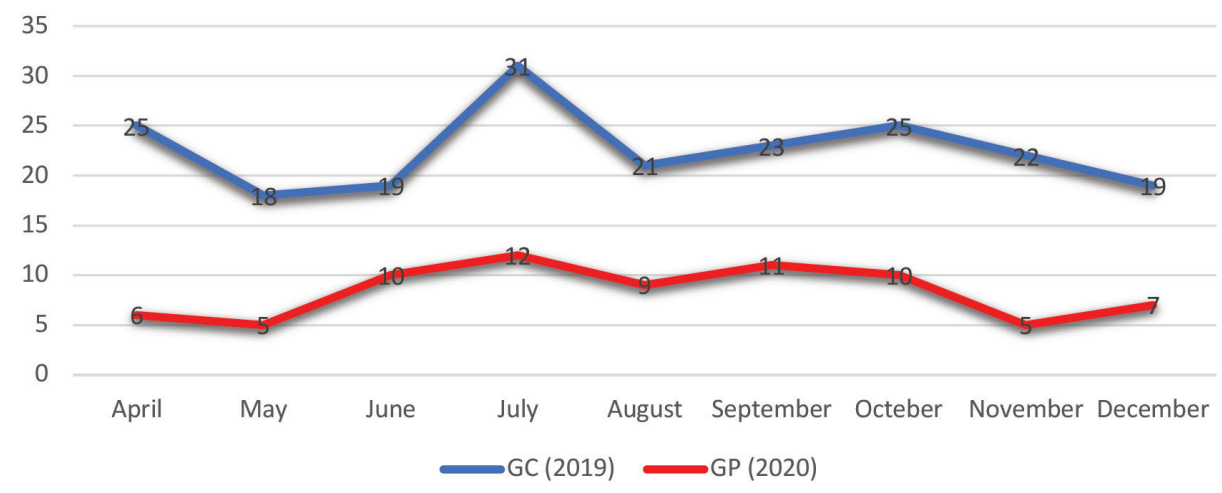

Figure 1. Number of patients with spinal trauma in GC and GP by months 
turkishspine

With the first case detected 2019, COVID-19 has gradually become a global pandemic. Some extraordinary measures and practices have been put in place in order to fight effectively against the pandemic. As part of this process, many hospitals have been transformed into pandemic hospitals. Since our hospital is consisted of two blocs, while one of these blocs has been turned into a pandemic hospital to admit exclusively the COVID-19 patients throughout the pandemic, the other bloc continued to admit trauma patients as usual, and the quality of the emergency department services remained same as the previous year. For this reason, throughout the pandemic, the emergency department continued to admit the trauma outpatients as well as the trauma patients transferred by ambulance. Contrary to expectations, even as many hospitals in our city closed their emergency departments to serve as pandemic hospital, the number of spinal trauma patients who visited our hospital decreased dramatically.

COVID-19 bans have been found to have a serious impact on trauma-related emergency department visits. There was a significant difference between the PG and the CG in terms of hospital visits with complaint of spinal trauma. Local and global public health measures such as the travel bans within and between the cities, traffic restrictions, lockdowns, curfews, quarantines have not only slowed down the spread of COVID-19 but also significantly reduced exposure to trauma.

Many studies in the literature focused on how to perform elective surgeries during the pandemic or the decreasing number of them. Few articles have written about performing emergency surgery in spinal trauma cases, and even few of them compare spinal trauma patients in the pre-pandemic and the pandemic period. The results of previous studies also confirm our study's results. For example, according to a research conducted on the pediatric population in Canada, comparison of two months of pandemic with the same period of the previous year demonstrated a reduction of 35 to $83 \%$ for different age groups ${ }^{(9)}$. Likewise, having compared a period of one month of the pandemic and the pre-pandemic, another study carried out in Italy reached similar results, showing

Table 2. Clinical features of spinal traumas according to groups

\begin{tabular}{|c|c|c|c|c|}
\hline Spinal trauma & & $\begin{array}{l}\text { Control } \\
\mathrm{n}(\%)\end{array}$ & $\begin{array}{l}\text { Pandemic group } \\
\text { n (\%) }\end{array}$ & $\mathbf{P}^{1}$ \\
\hline \multirow{5}{*}{ Type of injury } & Total & 203 (100\%) & 75 (100\%) & 0.919 \\
\hline & Traffic accident & 81 (40\%) & 29 (39\%) & \\
\hline & Falling (inside or outside) & $55(27 \%)$ & $20(27 \%)$ & \\
\hline & Occupational accident & $41(20 \%)$ & $14(18 \%)$ & \\
\hline & Others & $26(13 \%)$ & $12(16 \%)$ & \\
\hline \multirow{3}{*}{ Severity of injury } & Total & 203 (100\%) & 75 (100\%) & 0.121 \\
\hline & Multiple trauma & $32(16 \%)$ & $16(21 \%)$ & \\
\hline & Isolated spinal trauma & $171(84 \%)$ & 59 (79\%) & \\
\hline \multirow{5}{*}{ Trauma level } & Total & $203(100 \%)$ & 75 (100\%) & 0.315 \\
\hline & Lumbar & $136(67 \%)$ & $41(55 \%)$ & \\
\hline & Thoracic & 40 (20\%) & $17(23 \%)$ & \\
\hline & Cervical & $11(5 \%)$ & $7(11 \%)$ & \\
\hline & Multiple level & $16(8 \%)$ & $8(11 \%)$ & \\
\hline \multirow{3}{*}{ Neurologic deficit } & Total & 203 (100\%) & 75 (100\%) & 0.482 \\
\hline & Negative & $182(90 \%)$ & 65 (87\%) & \\
\hline & Positive & $21(10 \%)$ & $10(13 \%)$ & \\
\hline \multirow{3}{*}{ Treatment } & Total & 203 (100\%) & 75 (100\%) & 0.173 \\
\hline & Conservative & $95(47 \%)$ & $42(56 \%)$ & \\
\hline & Surgery & $108(53 \%)$ & 33 (44\%) & \\
\hline
\end{tabular}

Table 3. Comparison of groups according to the place of the fall

\begin{tabular}{llll}
\hline Falling place & $\begin{array}{l}\text { Control } \\
\mathbf{n}(\%)\end{array}$ & $\begin{array}{l}\text { Pandemic group } \\
\mathbf{n}(\%)\end{array}$ & p-value \\
\hline Inside of house & $25(45 \%)$ & $17(85 \%)$ & $\mathbf{0 . 0 0 2}^{1}$ \\
\hline Outside of house & $30(55 \%)$ & $3(15 \%)$ & \\
\hline Total & $55(100 \%)$ & $20(100 \%)$ & \\
\hline
\end{tabular}

${ }^{1}$ Chi-square test 
that the number of patients decreased dramatically (77$83 \%)^{(10)}$. Another study which covered all age groups found a $49 \%$ reduction in the number of patients ${ }^{(11)}$. We think that the main reason for this is the decrease in traffic accidents resulting from the reduced use of private cars and public transportation due to the pandemic-induced lockdowns and work from home. According to a study, the figures from some states of the USA showed that throughout the pandemic the number of traffic accidents dropped by $50 \%{ }^{(12,13)}$.

In our research, we found a $63 \%$ reduction in the number of emergency department visits during the pandemic. There was no difference between the CG and the PG in terms of the cause of injury, the place of injury in the spine and spinal cord, exhibition of multiple trauma or isolated spinal trauma depending on severity of the injury, presence of neurological deficits and treatment options. In addition, no significant difference was found in terms of patient age, gender and length of hospital stay. There was only a significant difference in the total number of patients between the two groups. It can be seen that the measures put in place to prevent spread of COVID-19 and bring down the number of cases have also protected people against trauma. Thus, exposure to trauma and spinal trauma patient visits have decreased.

During the pandemic, where lockdowns and work from home have become prevalent due to quarantines and curfews, the number of indoor falls, falls down stairs or falls into the gaps within the buildings increased significantly. At the same time, the number of outdoor falls (falls at workplace, school, sports centers, etc.) decreased. Although there is a significant decrease in the total number of traumas, indoor protective measures should be put in place. Areas that may cause indoor falls such as wet floors, stairs and steps should be carefully checked to make them safer.

Consistent with our hypothesis, as a result of quarantines, lockdowns, curfews, work from home and travel bans, a significant decrease was observed in the number of patients visiting emergency departments ${ }^{(12,13)}$. Primordial prevention is an important public health matter. Pandemic measures such as quarantines, lockdowns, curfews and travel bans put in place to reduce the transmission and spread of the disease also protected people from trauma.

If we consider this lockdown as a primordial prevention such as wearing seat belts to prevent injuries in traffic accidents, wearing helmets to prevent injuries in motorcycle accidents, wearing protective equipment to prevent injuries in sports and workplace accidents, we think that lockdowns have been particularly effective in preventing trauma. We also think that compliance with traffic rules, using the right protective equipment, ensuring workplace security, creating remote jobs or hybrid work models (part-time office jobs/part-time remote jobs) for some desk workers, and strictly following the precautions in the post-pandemic normalization period will significantly reduce exposure to trauma and emergency department visits.
The main strength of our study is that it examines a relatively longer period (nine months) and compares it to the prepandemic period. Studies in the literature have focused on one to three months. In our study, however, a period of nine-month was examined.

\section{Study Limitations}

The main limitation of this study is that it is based on data from only one hospital. In addition, we evaluated only the outpatients visiting the emergency department, thus the patients transferred by ambulance was not included in the sample. It is also possible that as patients know that most of the state hospitals have been turned into pandemic hospitals, they may have visited private hospitals and medical centers with no or fewer COVID-19 patients to avoid infection.

\section{CONCLUSION}

The pandemic restrictions put in place to prevent the spread of the infection also led to a decrease in the number of spinal traumas. The lessons learned during the pandemic will guide us in our fight against spinal trauma and all other types of trauma when we return to normalcy in the post-pandemic era.

\section{Ethics}

Ethics Committee Approval: Ethical approval was obtained from both the local ethics committee University of Health Sciences Turkey, Gaziosmanpaşa Training and Research Hospital (approval date: 28.04.2021, approval number: 259) and the Ministry of Health.

Informed Consent: Written informed consent for scientific purposes and clinical data collection were obtained from patients according to institutional protocol.

Peer-review: Internally peer-reviewed.

\section{Authorship Contributions}

Surgical and Medical Practices: Ö.Ö., Concept: Ö.Ö., F.D., Design: Ö.Ö., O.B., E.C., Data Collection or Processing: Ö.Ö., M.K.,Analysis or Interpretation: Ö.Ö., S.K., E.C., Literature Search: Ö.Ö., Writing: Ö.Ö., E.C.

Financial Disclosure: The authors declared that this study received no financial support.

Conflict of Interest: The authors have no conflicts of interest to declare.

\section{REFERENCES}

1. Niemi-Nikkola V, Saijets N, Ylipoussu H, Kinnunen P, Pesälä J, Mäkelä $\mathrm{P}$, et al. Traumatic spinal injuries in Northern Finland. Spine 2018;43:E45-51.

2. Liu B, Zhu Y, Liu S, Chen W, Zhang F, Zhang Y. National incidence of traumatic spinal fractures in China: data from China National Fracture Study. Medicine (Baltimore). 2018;97:e12190.

3. Hasler RM, Exadaktylos AK, Bouamra O, Benneker LM, Clancy $\mathrm{M}$, Sieber R, et al. Epidemiology and predictors of spinal injury in adult major trauma patients: European cohort study. Eur Spine J. $2011 ; 20: 2174-80$. 
turkishspine

4. Cooper C, Atkinson EJ, O'Fallon WM, Melton 3rd LJ. Incidence of clinically diagnosed vertebral fractures: a population-based study in Rochester, Minnesota, 1985-1989. J Bone Miner Res. 1992;7:221-7.

5. Hu R, Mustard CA, Burns C. Epidemiology of incident spinal fracture in a complete population. Spine 1996;21:492-9.

6. Moradi-Lakeh M, Rasouli MR, Vaccaro AR, Saadat S, Zarei MR, RahimiMovaghar V. Burden of traumatic spine fractures in Tehran, Iran. BMC Public Health. 2011;11:789

7. Daly MC, Patel MS, Bhatia NN, Samuel BS. The influence of insurance status on the surgical treatment of acute spinal fractures. Spine. 2016;41:37-45.

8. Wang $\mathrm{H}$, Zhang $\mathrm{Y}$, Xiang Q, Wang X, Li C, Xiong H, et al. Epidemiology of traumatic spinal fractures: experience from medical universityaffiliated hospitals in Chongqing, China, 2001-2010. J Neurosurg Spine. 2012;17:459-68.

9. Keays G, Friedman D, Gagnon I. Original quantitative researchPediatric injuries in the time of COVID-19. Health Promot Chronic Dis Prev Can. 2020;40:336.
10. Lazzerini M, Barbi E, Apicella A, Marchetti F, Cardinale, F, Trobia G. Delayed access or provision of care in Italy resulting from fear of COVID-19. Lancet Child Adolesc Health. 2020;4:e10-e11.

11. Tamburrelli FC, Meluzio MC, Perna A, Santagada DA, Genitiempo $M$, Zirio G, et al. Spinal surgery in COVID-19 pandemic era: One trauma hub center experience in central-southern Italy. J Orthop. 2020;22:291-3.

12. Shilling, F. Special Report 3: impact of COVID19 mitigation on traffic, fuel use and climate change [Internet]. Davis (CA): University of California; 2020 Apr [cited 2020 May 28]. Available from: https:// roadecology.ucdavis.edu /files/content/projects/COVID_ CHIPs_ Impacts_updated 430.pdf

13. Kopf D. Traffic collisions are plummeting in several US cities [Internet]. New York (NY): Quartz. 2020 Mar 20 [cited 2020 May 28]. Available from: https://qz.com/1822492/traffic -accidents-are-plummetingbecause -of-the-pandemic 